interest with enough technical detail to make the basic cryptographic principles intelligible to a lay reader. My only regret is that he did not give more weight to authentication and other aspects of cryptography besides secrecy, for example the role of digital signatures in electronic commerce.

By contrast, Marks' technical explanations are not always intelligible, and are sometimes buried in a torrent of colourful language: "The ladies of the First Aid Nursing Yeomanry, otherwise known as the coders of Grendon, had force-fed their eight indecipherables with a diet of transposition keys and all but one of the invalids had responded to treatment. The malingerer was waiting on my desk with a curt note from the Grendon supervisor acknowledging defeat."

Nonetheless, Marks' book makes exciting reading, and is full of information and opinions one cannot find elsewhere. Much of the information in Singh's book can be found elsewhere, but not in such an accessible and enjoyable form.

Charles H. Bennett is at the IBM T. J. Watson Research Center, PO Box 218, Yorktown Heights, New York 10598, USA.

\section{.......................... \\ A compendium of Victorian culture}

\section{The Great Exhibition}

by John R. Davis

Sutton: 1999. 238 pp. $£ 20, \$ 36$

The Great Exhibition of 1851: A Nation on Display

by Jeffrey A. Auerbach

Yale University Press: 1999. 278 pp. \$40, £25

\section{Sophie Forgan}

The Great Exhibition occupies one of those hallowed places in history as the first and most successful of its type. It certainly had the stuff of myth in its making. The troubled background of recent revolutionary unrest in Europe, the near-disaster of the architectural design rescued by Joseph Paxton's blotting-paper sketch, the fairytale 'crystal' quality of the building which gave it its name, its huge size, the overwhelming number and richness of the exhibits gathered from all corners of the globe, the unsurpassed crowds of orderly visitors, the message of peaceful internationalism and free trade preached by its supporters - all confirm the impression of Victorian Britain at the height of its power.

The material continues to provide an inexhaustible source of anecdotes: for example, the highest tender (not accepted) for servicing the refreshment rooms came from a well-known London brothelkeeper, and the exhibition provided the launching pad for Messrs Schweppes' long

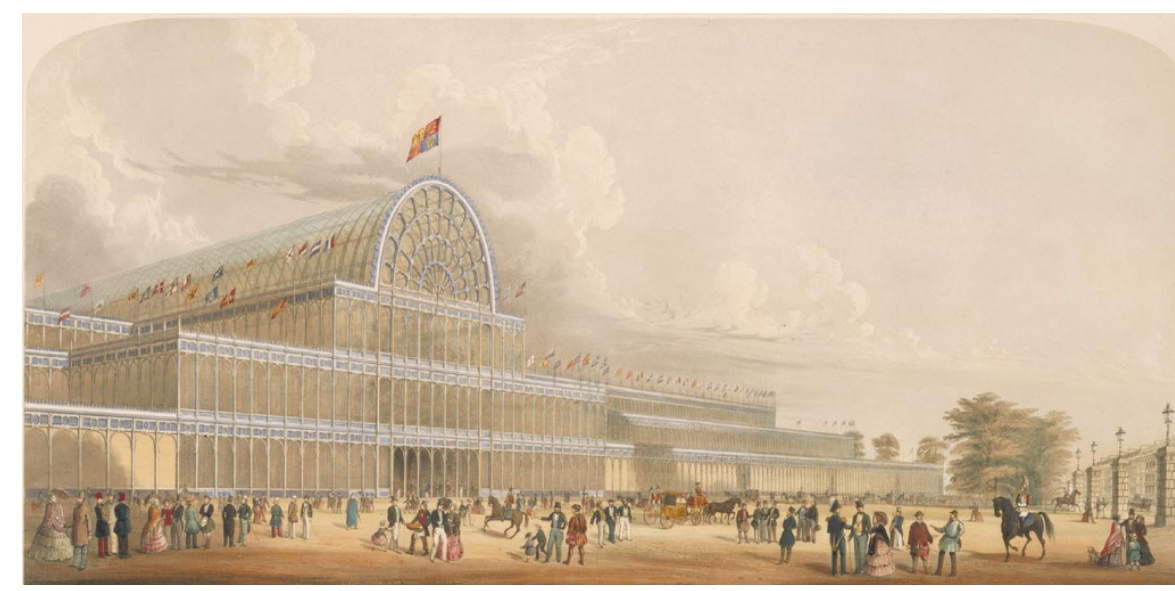

A heroic national achievement, or an object lesson in taste, mostly bad?

involvement in the soft-drinks industry.

A reassessment is timely. In 1950, Charles Gibbs-Smith viewed it as a heroic national achievement; Nikolaus Pevsner saw it as an object lesson in taste, mostly bad; Asa Briggs argued in 1954 that it was a defining moment in the formation of middle-class political and economic values, although his later work in 1988 viewed it as a compendium of 'things', of Victorian material culture. Others see it as the birthplace of modern consumer culture.

Both authors here take much from previous studies, but have their own perspectives. John Davis is particularly concerned with the political and economic context in which the exhibition evolved, and the way that exhibitions could help transform people's ideas about industrialization and modernity. His analysis of the "modernizing agenda" of the organizers has a distinctly familiar feel. Jeffrey Auerbach, on the other hand, is more interested in the exhibition as a "cultural battleground", in which ideas about national identity were forged. Both argue that the exhibition could mean quite different things to different groups, and that that was an important reason for its success.

Fully half of each book is devoted to the background and preparations for the exhibition. Davis is particularly interesting about earlier French and German exhibitions, the former having an aesthetic focus and the latter a more overtly educational agenda. The road from the original idea for a national industrial exhibition to the international exhibition of the works of industry of all nations in Hyde Park was tortuous and uncertain. The shifts of aim are carefully charted as the organizers responded to the need to gain support and encompass a broader section of the nation. It was a minor miracle that the exhibition took place at all.

Each author has valuable points to make about the choice and layout of the exhibits. Large, piled-up 'trophy' exhibits in the central avenue revealed the organizers' priorities; they generally put art or colonial raw materials in the most prestigious place. Technology and moving machinery were popular, especially working exhibits. Visitors could watch the entire process of cotton production from spinning to finished cloth. Scientific instruments were found in class $\mathrm{X}$, and included electric telegraphs, microscopes, air pumps and barometers, as well as musical, horological and surgical instruments.

Both authors tally the number of medals awarded, either for workmanship (Prize medals) or for novelty of invention or application (Council medals). They conclude, as did some scientific contemporaries, that the British had few reasons for complacency. Auerbach is better informed about relevant work in scientific history, but perhaps he accepts Charles Babbage's 'decline of science' view too readily.

The arguments both before and after the exhibition about the role of scientific and technical education in industrial progress are well aired. And the book recognizes the importance of the chemist Lyon Playfair in organizing the exhibition and helping with the classification of objects. Already a protégé of Sir Robert Peel, the former Tory prime minister, he became a protégé of Prince Albert, helped by the fact that he was also a German speaker and did his research training in Germany.

Although both books tell a similar story, their emphases are different and there is surprisingly little overlap. Davis is more sure-footed in terms of the political entanglements; Auerbach has more material on what people actually thought about the exhibition. One has a real sense of how the Great Exhibition happened and what it looked like, a vast bazaar with palm trees, flowers, organ music and the clank of machinery. Both books provide a treasure trove of pictures, many of them unfamiliar. The exhibition could clearly encompass a wide variety of meanings and interests. Minor quibbles apart, it seems that, rather like the Great Exhibition itself, there is something for everyone here.

Sophie Forgan is in the Department of Law, Arts and Humanities, University of Teesside, Middlesbrough TS1 3BA, UK. 